\title{
The Character of Successful Trainings with Serious Games
}

\author{
$\underline{\text { doi:10.3991/ijet.v5s3.1498 }}$ \\ T. Becker \\ Bildungsberatung Till Becker \& Co. GmbH, Waiblingen, Germany
}

\begin{abstract}
This paper gives a basic guideline for the development of trainings using serious games. It describes a framework for the training with serious games. It shows how to define a training goal and describes the process of learning to reach this goal. It points out a methodology how to design successful trainings with serious games.
\end{abstract}

Index Terms-Game, Simulation, Training, Software

\section{SERIOUS GAMES}

"A serious game is a game designed for a primary purpose other than pure entertainment. The "serious" adjective is generally appended to refer to products used by industries like defense, education, scientific exploration, health care, emergency management, city planning, engineering, religion, and politics.” [1]

With this search result we found out two important points. The proposition of a serious game is not pure entertainment and it is used by industries. Following this definition:

In this article the first proposition is that a serious game is for training.

The second proposition is that it is used in a real life context, the game is authentic. This is a dissociation to "off the shelf games" in training arrangements [2].

If we take business trainings as an example for further education we can see that there are thousands of training solutions for business and finance. In most cases they rely on a drill-and-practice-pattern and impart only theoretical and expert knowledge. These solutions are often brilliant within their framework but lack practical aspects. And often misses the relevance for the learner.

With this idea we've gotten the first point of success for trainings - relevance of the content and a training aim. For example we can take the field of entrepreneurship training.

Many of the solutions offered in this area rely on the procurement of theoretical and expert knowledge presented in a training framework. What may be ideal for tax accountants or book-keepers is not enough to promote entrepreneurial thought on a large scale. The entrepreneur needs additional abilities and skills to successfully develop his ideas into a business model. In most cases he or she may buy external expert knowledge - while an entrepreneurial character can only be developed personally.

So, if we're planning a relevant training we must ensure to hit the relevant aims of the learner and the defined learning goals. In the example above the entrepreneur is a person who wants to bring an idea to the market. Not to fill in annual tax declarations correctly.

\section{RELEVANT TRAining GoAls AND CONTENT}

There are some questions to find out what is relevant for the training.

- What is my training goal?

- Who is the target group?

- What kind of media is useful to hit the training goal and can be used by the target group?

- In which framework the training is taking place?

- What are the environmental constraints of the learning environment?

- What are the general conditions for the planned training?

\section{A. Training goal}

According to Benjamin Blooms [3] taxonomy of learning domains there are three domains with several learning goals:

\section{B. Cognitive learning goals: mental skills (Knowledge)}

The cognitive domain involves knowledge and the development of intellectual skills. This includes the recall or recognition of specific facts, procedural patterns, and concepts that serve in the development of intellectual abilities and skills. There are six major categories, which are listed in order below, starting from the simplest behavior to the most complex. The categories can be thought of as degrees of difficulties. That is, the first one must be mastered before the next one can take place.

1) Categories

- Knowledge: Recall data or information.

- Comprehension: Understand the meaning, translation, interpolation, and interpretation of instructions and problems. State a problem in one's own words.

- Application: Use a concept in a new situation or unprompted use of an abstraction. Applies what was learned in the classroom into novel situations in the work place.

- Analysis: Separates material or concepts into component parts so that its organizational structure may be understood. Distinguishes between facts and inferences.

- Synthesis: Builds a structure or pattern from diverse elements. Put parts together to form a whole, with emphasis on creating a new meaning or structure.

- Evaluation: Make judgments about the value of ideas or materials. 


\section{Affective learning goals: growth in feelings or emotional areas (Attitude)}

The affective domain [4] (Krathwohl, Bloom, Masia, 1973) includes the manner in which we deal with things emotionally, such as feelings, values, appreciation, enthusiasms, motivations, and attitudes. The five major categories are listed from the simplest behavior to the most complex:

\section{1) Categories}

- Receiving Phenomena: Awareness, willingness to hear, selected attention.

- Responding to Phenomena: Active participation on the part of the learners. Attends and reacts to a particular phenomenon. Learning outcomes may emphasize compliance in responding, willingness to respond, or satisfaction in responding (motivation).

- Valuing: The worth or value a person attaches to a particular object, phenomenon, or behavior. This ranges from simple acceptance to the more complex state of commitment. Valuing is based on the internalization of a set of specified values, while clues to these values are expressed in the learner's overt behavior and are often identifiable.

- Organization: Organizes values into priorities by contrasting different values, resolving conflicts between them, and creating an unique value system. The emphasis is on comparing, relating, and synthesizing values.

- Internalizing values (characterization): Has a value system that controls their behavior. The behavior is pervasive, consistent, predictable, and most importantly, characteristic of the learner. Instructional objectives are concerned with the student's general patterns of adjustment (personal, social, emotional).

\section{Psychomotor learning goals: manual or physical} skills (Skills)

This domain is not relevant for the serious games discussed in this article. Of course everybody using a computer is learning to coordinate hand and eye. But this aim is not relevant for the sector of serious games. Sometimes producers of Ego shooters use this argument as a fig leaf for their "content".

\section{FRAMEWORK}

If it is planned to use a serious game for training the didactical concept is a constructivist learning arrangement. The learning goal is defined with the taxonomy above and the pedagogical concept is given by the media "serious game”.

[The concept of a constructivist view of learning was developed by Piaget [5] who believed that learning is not transmitted passively "Nürnberger Trichter" [6], but attained through well-defined stages by active participation of a learner. Some concepts focus on the importance of socio-cultural activity in learning in addition to introduce flexible stages of development [7]. The importance of context and "authenticity" in learning has been emphasized by Brown, Collins and Duguid [8]. According to them, "authentic activity is the ordinary practices of cultures". Lave and Wenger [9] further extend this view in their influential work on situated learning to point out that, "...Learning occurs through centripetal participation in the learning curriculum of the ambient community" [p. 100]. Where the learning curriculum consists of "...situated opportunities (thus, including exemplars of various sorts often thought of as “goals”)” [p. 97]]

For the concept of trainings with serious games, constructivist authentic learning environments are defined as those learning environments whose design is consistent with the principles of the more recent constructivist tradition of how people learn.

They typically provide authentic contexts and activities, access to expert knowledge, and support multiple roles and perspectives, and they support the collaborative construction of knowledge [10].

\section{A. Framework concept for the successful use of serious games in training}

The main part of the framework is the concept of a learning curriculum. This curriculum consists of situated authentic working tasks derived from authentic situations and a formal structured set of content (see figure1).

The primary components of the framework used to describe a learning curriculum are shown in Figure 2. The "Business process derived from the real world" is a description of an authentic situation or scenario which is derived from the real world situation of the learner (e.g. function, event, role, performance parameter). The "available information" of the business process / authentic situation is enhanced by additional artifacts derived from the process such as books, manuals and existing databases as well as interaction with other learners, experts and trainers. If a performance parameter has a specific value, then a specific, "successful action" by the learner is required to bring this value to another/successful level [11].

The "task business process" is the subset of the authentic situation that is relevant to the learner.

The "adaptation" is the primary construct in this framework and represents what is "learned" under the constraints of the "task business process" and the constraints/competencies from the learner. The "constraints of the learner" contains behavioral competencies like cognitive constraints (e.g. short-term memory, processing capabilities) and learning styles (e.g. holistic, analytical, field independent vs. field dependent) on the one hand and "goals and motivation" (performance criteria) on the other hand [12]. This is the learners' environment which is addressed by, e.g., a trainer or coach. In the examples, the learners can also have self-motivated/intrinsic goals, e.g., to perform the business process, increase their work performance, enhance their employability, etc.

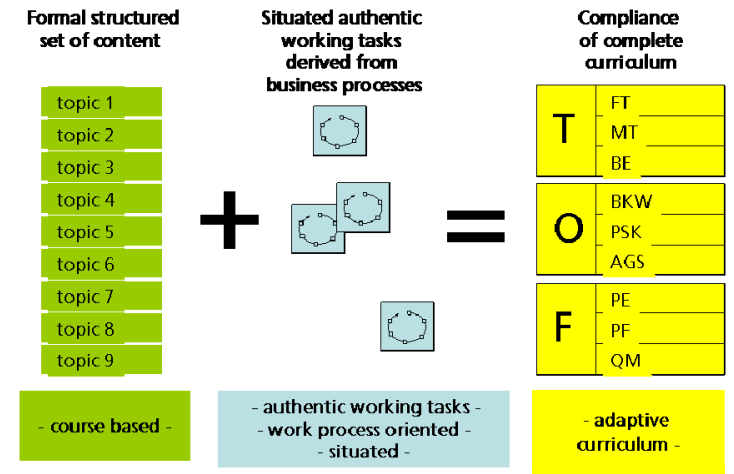

Figure 1. Curriculum of situated authentic working tasks and formal structured set of conten 


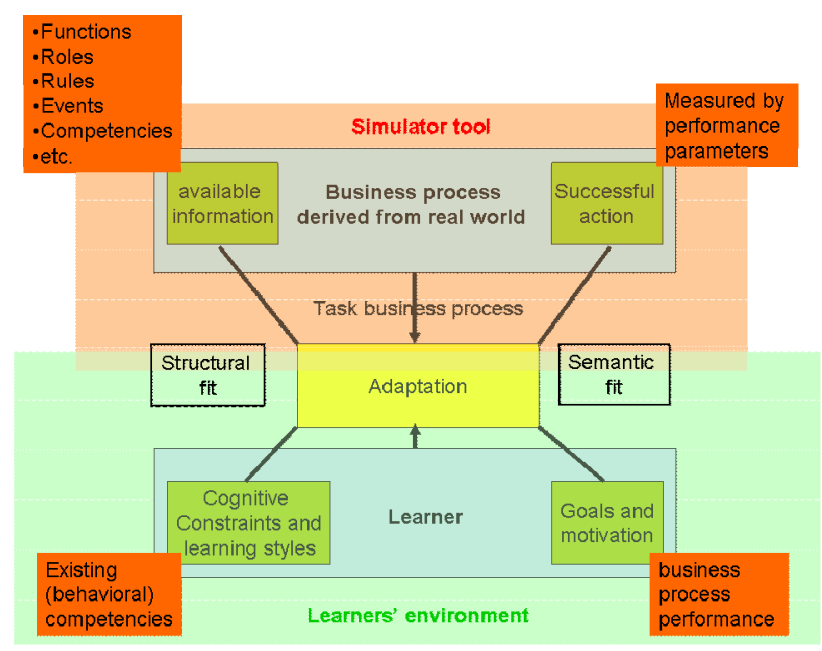

Figure 2. Framework for an authentic constructivist learning environment using a simulator for adaptation

The first key construct in the framework is the "adaptation" itself. Adaptation is a construct that develops under the constraints of the task business process derived from the real world and the learner [13].

The "adaptation" is nothing the learner learns or has. It is a construct that represents what evolves as a set of routines (including asking for, and retrieving information, for example) or dynamics that allow the learner to be "fit" for the particular business process.

The second key construct of the framework is the concept of "fit". The fit describes how well a learner is adapted to the chosen business process. Fit can be classified into two dimensions; semantic and structural.

The semantic dimension is a measure of how well the learner's actions are acceptable in the particular process. The semantic fit is therefore primarily related to how well the goals and the intentions of the learner are realized in the actions he/she takes in the authentic situation simulated.

The structural dimension of fit describes how closely the cognitive constraints and learning styles of the learner "match" the information present in the business process (e.g. does the business process manager accept a particular type of process documentation as suited to her/his skills?). Manifestation of failure of structural fit occurs when, for example, an individual refuses to accept the information provided in the process as "valid" for their own task.

\section{B. Authentic learning environments}

Authentic learning environments in the constructivist tradition are situations that allow a learner to create his/her own personal knowledge in a particular task environment. In simplified manifestation, an authentic learning environment is a substitute to the actual problem-solving environment (e.g. an authentic situation as opposed to the simulated situation).

An authentic learning environment can be described more generally as a manifestation of a "learning curriculum”. So in terms of the framework, the learning curriculum is simply a set of situated opportunities that allow the adaptation to eventually attaining a high degree of fit between the situation and the learner.

The design of a good authentic learning environment therefore consists of creation of an appropriate set of situ- ated opportunities. The situated opportunity can be described by four parameters/characteristics/properties:

1. Information about the situation

2. Successful actions in situation

3. Cognitive constraints and learning styles of the learner

4. Goals and intentions of the learner

A successful authentic situation as a learning environment has to create enough (and the right) situated opportunities to ensure that the adaptation which arises for a specific learner has both a high structural as well as a semantic fit.

A fundamental problem that arises with using simulated processes is their validity. How does one ensure, for example, that adaptation thus evolved within the simulated process will in fact transfer to the real situation? The key problem that needs to be solved in developing an authentic constructivist environment, therefore, is to ensure that adaptation which emerges in response to the "fit" requirements (both semantic and structural) of the constructed authentic process, also establishes a high degree of fit in the real situation [14]. This is what the framework and the resulting methodology helps to achieve.

\section{Methodology}

This section presents the various dimensions of a typical authentic learning environment and shows how the framework presented earlier provides conceptual footing for a development methodology based on a pedagogical design, architectures, the environmental context and the learning objective. A methodology is derived from these sub sections [15], where each sub section is tied to exploring one dimension.

\section{A. Complete pedagocical design}

The primary objective of this step is to determine what constitutes a "situated opportunity" within a particular pedagogical design example. A pedagogical design imposes broad constraints on what a situated opportunity can be. In doing so, it outlines the possible space of situated opportunities for the learning environment. In addition, based on the properties of the semantic and structural fit in the real business process, pedagogical design also determines constraints on the four components of a typical situated opportunity.

It doesn't matter what the manifestation of the pedagogical design of an authentic environment is, each has to pay particular attention to how and why the situated opportunities thus created are authentic. For example, in problem-based learning, e.g. a convincing problem is created and learners are supported by input received from various information sources. The main premise behind these environments is to allow the learners to make mistakes in a "safe" context and to receive feedback as a third-person. A problem consists of the information presented in the environment (1.) and the feedback provided by the resulting parameters guides the learner on what is a successful action (2.) through failure. The problems have to be consistent the learner's objectives (4.) as well as the cognitive constraints (3.). 


\section{B. Construct achitecture for a authentic environment}

The primary objective of this step is to specify an architecture that provides appropriate support for the situated opportunities outlined in the previous step.

The architecture of an authentic environment specifies the various components that must exist in a learning environment or a computer manifestation of it. A general characterization of the constructivist learning environments has been provided by Jonassen, Peck and Wilson [16].

The components needed for such environments are:

- problem/project space. The learners are presented with an interesting, relevant and engaging problem. This is simply the creation of a single situated opportunity,

- related Cases. When learners are expected to solve problems, they must be provided with a set of related experiences on which the learners' can draw. These represent a set of situated opportunities similar to the one being presented,

- an information source which provides learners with information they need in a short time in the right format. This simply stresses the information component (1.) of the situated opportunity,

- cognitive (knowledge) construction tools. Tools that support the learner's abilities to solve the tasks at hand. These are a part of the physical environment (e.g. a paper and a pencil, a calculator, a utility program) if the fit determines the learner's cognitive constraints (3.) need to be augmented to achieve an appropriate fit,

- conversation (knowledge-negotiation) tools. Tools to support collaboration. These are a part of the physical environment, if accessing information (1.) or successful action (2.) requires external conversations and

- social/contextual support. Physical, organizational, political and cultural aspects of the environment. This can be related primarily to the learner's motivation and goals (4.).

\section{Consider context of learning}

The primary objective of this step is to ensure that the environmental constraints of the learning environment have been considered for the architecture proposed in the previous steps.

Authentic learning environments exist in a context. The environmental context of an intelligent tutoring system as described by Kinshuk, Opperman and Russel [17] can also be applied to an authentic learning environment.

The context is divided into seven categories:

- learner (natural abilities, learning styles and motivation),

- peers (interaction with fellow students),

- social environment (social values, institutional values, evolution of common metaphors),

- trainer (teaching styles, personality attributes),

- branch (homogeneity, operational/conceptual, physi$\mathrm{cal} /$ virtual, teaching traditions, levels),

- characteristics of knowledge (operational, causal, contextual) and

- characteristics of medium (hardware, software and communication capabilities).

\begin{tabular}{|c|c|c|c|c|}
\hline \multirow[b]{2}{*}{$\begin{array}{l}\text { business } \\
\text { process } \\
\text { context }\end{array}$} & \multicolumn{4}{|c|}{ Framework } \\
\hline & $\begin{array}{c}\text { available } \\
\text { informa- } \\
\text { tion }\end{array}$ & $\begin{array}{l}\text { Success- } \\
\text { ful ac- } \\
\text { tion }\end{array}$ & $\begin{array}{l}\text { Cognitive } \\
\text { Con- } \\
\text { straints } \\
\text { and learn- } \\
\text { ing styles }\end{array}$ & $\begin{array}{l}\text { Goals } \\
\text { and } \\
\text { motiva- } \\
\text { tion }\end{array}$ \\
\hline Learner & & & + & + \\
\hline Peers & & & & + \\
\hline $\begin{array}{l}\text { Social envi- } \\
\text { ronments }\end{array}$ & & & & + \\
\hline Trainer & + & + & & + \\
\hline Branch & + & & & \\
\hline $\begin{array}{l}\text { Characteris- } \\
\text { tic of } \\
\text { Knowledge }\end{array}$ & + & & + & \\
\hline $\begin{array}{c}\text { Characteris- } \\
\text { tic of } \\
\text { Media }\end{array}$ & & & + & \\
\hline
\end{tabular}

Figure 3. Relationship between framework and business process context

From the perspective of the framework, these categories roughly map as shown in Figure 3.

It is interesting to note that the trainer or the teaching style maps mostly provides the available information (what it provided to the learner), successful action (guiding through assessment) and motivation. Most traditional instructional theories can in fact be used to create these parts of situated opportunities as they rely largely on information (1.) and successful action (2.) and are generally concerned with how to enable a learner to do something (as the goals are prescribed by the trainer).

\section{Consider general conditions of training}

The primary objective of this step is to ensure that the general conditions of the learning environment have been considered. The general conditions, as distinguished from the social environment above, are more independent from the training itself. This point is the most important for the successful use of serious games. From a theoretical didactical aspect a serious game has a lot of advantages. But a successful serious game is used in reality not in a laboratory. If it is missed during the planning and production phase of a serious game to consider the following listed points. The result is a "nice" research result but not a useful training media.

- In most of the cases a lesson has 45 min. Also business trainings have fixed time slots, often oriented on the 45 min of school lessons. In most of the cases they are doubled to $90 \mathrm{~min}$. In this time it must be possible to introduce into the game, to play a sequence of the game and to debrief the game to set a learning anchor with the experiences the learners made. Otherwise it is just a game not a serious game for training purposes.

- During the game all participants must be in nearly the same "game time"/timeline. Otherwise it is not possible to compare the results of different learners and to discuss about the individual experiences in the debriefing phase. The idea that every body plays at is own and then there is a joint debriefing doesn't work real. A lot of business trainings are not based on an 
intrinsic motivation of the participants. Most of the participants were send by the boss to such trainings.

- The teacher must prepare trainings in a personal effective way. A teacher will not play two weeks a serious game to use it in 2 lessons a year. Preparation and benefit for the lesson must be in the right balance. Otherwise the teachers and trainers won't use the serious game. Believe it or not, also teachers take the way of the lowest resistance in preparing their lessons.

- The important point is to think about the ITinfrastructure at training providers. Often they have old hardware. A serious game which works perfect on a developer computer will often have problems on a training computer. If there is only one problem with game most of the users won’t use it once again.

\section{CONCLUSION}

For a successful training with serious game it is important to consider some points before producing such a training media. It is important to consider the following aspects. Define an individual learning goal first and be aware that the taxonomy form Bloom is build hierarchically. Consider the framework of your training. To make a serious game attractive it is a success factor to find an authentic story and scenario for the game.

Plan a training using a serious game in a complete pedagogical design: introduction - execution (information presented in the environment (1.) and the feedback provided by the resulting parameters guides the learner on what is a successful action (2.) through failure. The problems have to be consistent the learner's objectives (4.) as well as the cognitive constraints (3.)) - debriefing

Build an architecture for an authentic environment and consider the context of learning. Also consider the general conditions where the training is executed and adopt the game to different conditions.

A serious game for training purposes must be planned by using the ideas above. If the motivation is to have a "cool" training tool, to fill missing work orders in at game development company or to use it for marketing of a training company, a serious game is the wrong tool. A real serious game is too expensive for such reasons. A cheep way to hit those aims is to integrate small video game sequences in a standard training course as a reward for a right answer. That's cheep, looks cool and is good for marketing but it is not a serious game.

\section{REFERENCES}

[1] http://en.wikipedia.org/wiki/Serious game.

[2] For example: Charsky, d., Mims, C., 2008: Integrating Commercial Off-the-Shelf Video Games into School Curriculums. In: Tech Trends, Volume 52, Number 5, p. 38 - 44, Springer Boston, 2008

[3] Bloom, B. S. 1956. Taxonomy of educational objectives (Handbook 1: The cognitive domain), New York, Addison-Wesley.
[4] Krathwohl, Bloom, Masia, 1973, Taxonomy of Educational Objectives, the classification of educational goals- (Handbook II: Affective Domain), New York: McKay

[5] Piaget, J. (1975). The construction of reality in the child, Ballantine Books.

[6] Harsdörffer, G. P. (1647): Poetischer Trichter. Die Deutsche Dicht- und Reimkunst, ohne Behuf der lateinischen Sprache, in VI Stunden einzugießen. Nürnberg, Germany

[7] Vygotsky, L. S. (1980) Mind in society: The development of higher psychological processes, Cambridge, MA, USA: Harvard University Press.

[8] Brown, J. S., Collins, A., \& Duguid, P. (1989) Situated cognition and the culture of learning. Educational Researcher, 18 (1), 32-42.

[9] Lave, J. (1988) The culture of acquisition and the practice of understanding. IRL report 88-00087, Palo Alto, CA: Institute for Research on Learning.

[10] Zualkernan, I. A. (2006) A framework and a methodology for developing authentic constructivist e-Learning environments. Educational Technology \& Society, 9 (2), 198-212.

[11] Turvey, M. T., Carello, C., Kim, N (1981) Cognition: The view from ecological realism. Cognition, 10 (1-3), 313-321. doi:10.1016/0010-0277(81)90063-9

[12] Zualkernan, I. A. (2006) A framework and a methodology for developing authentic constructivist e-Learning environments. Educational Technology \& Society, 9 (2), 198-212

[13] Simon, H. A. (1996). The sciences of the artificial, Cambridge, MA, USA: MIT Press.

[14] Zualkernan, I. A. (2006) A framework and a methodology for developing authentic constructivist e-Learning environments. Educational Technology \& Society, 9 (2), 198-212

[15] cf. Zualkernan, I.A. 2006

[16] Jonassen, D. E., Peck, K. L., \& Wilson, B. G. (1998) Learning with technology: A constructivist perspective, Prentice-Hall.

[17] Kinshuk, P. A., Oppermann, R., Russell, D. (2001) Role of human teacher in web-based intelligent tutoring systems. Journal of Distance Learning, 6 (1), 26-35.

\section{AUTHOR}

T. Becker is CEO of the Bildungsberatung Till Becker \& Co. GmbH, Brunnweinbergstr. 24, 71334 Waiblingen, Germany (e-mail: till.becker@lernkultur-online.de), he has his first profession after a vocational training as an electronic technician. After that he made his studies in social science at the University of Duisburg. Then he was working as a researcher in a Media agency in Frankfurt. After that he changed in 2001 to the Fraunhofer IAO in Stuttgart. The main working areas are concepts for work place learning and training and the question how to shrink learn, and work processes to solve the upcoming challenges in a modern work force. In 2007 he founded the Bildungsberatung as a Spin-off from Fraunhofer IAO.

This paper is an extended version of a presentation given during the "Creative Learning with Serious Games" workshop during the "Fun and Games 2010" conference in Leuwen on 15 September 2010, and was supported by the e-VITA European Life Experiences”, project $\mathrm{nr}$ 143526-LLP-1-2008-1-IT-KA3-KA3MP.

Submitted October $31^{\text {st }}$, 2010. Published as resubmitted by the authors November $11^{\text {th }}$, 2010. 